\title{
RECANATI ON THE SEMANTICS/PRAGMATICS DISTINCTION
}

\author{
MANUEl García-CARPINTERo \\ Departament de Lògica, Història i Filosofia de la Ciència \\ Universitat de Barcelona \\ m.garciacarpintero@ub.edu
}

SUMMARY: One of the hottest philosophical debates in recent years concerns the nature of the semantics/pragmatics divide. Some writers have expressed the reserve that this might be merely terminological, but in my view it ultimately concerns a substantive issue with empirical implications: the scope and limits of a serious scientific undertaking, formal semantics. In this critical note I discuss two arguments by Recanati: his main methodological argument — viz. that the contents posited by what he calls 'literalists' (which are, on my own view, the very same ones that theoreticians in the formal semantics tradition seek to characterize) play no relevant role in communication - , and some phenomenological considerations regarding the "Availability Principle" that he appeals to in order to buttress that main argument.

KEY WORDS: semantics/pragmatics, truth-conditional content, literal meaning, communication

RESUMEN: Uno de los más encarnizados debates filosóficos recientes atañe a la naturaleza de la distinción entre semántica y pragmática. Aunque algunos autores han expresado reservas en el sentido de que éste pudiera ser sólo terminológico, en mi opinión tiene que ver con una cuestión sustantiva con implicaciones empíricas: el alcance y los límites de una empresa científica seria, la semántica formal. En este texto discuto dos argumentos de Recanati: su principal argumento metodológico, que los contenidos postulados por los autores que él denomina "literalistas" (los cuales, desde mi punto de vista, son justamente los que los teóricos de la semántica formal intentan caracterizar) no desempeñan ningún papel relevante en la comunicación, y, en segundo lugar, ciertas consideraciones fenomenológicas en torno a su "Principio de Accesibilidad", a las cuales apela para apoyar el argumento metodológico.

PALABRAS CLAVE: semántica/pragmática, contenido, condiciones de verdad, significado literal, comunicación

One of the hottest philosophical debates in recent years, and a very fruitful one in my view, concerns the nature of the semantics/pragmatics divide. Some writers have expressed the reserve that this might be merely terminological, but -even though terminological matters are of course involved - it ultimately concerns in my view an issue with empirical implications: the scope and limits of a serious scientific undertaking, formal semantics. Richard Montague (1973) — who inaugurated that research tradition by convincing linguists, through the example of his "proper treatment of quantification" system, that tools developed in mathematical logic can be 
helpfully deployed to explain features of natural languages - paradoxically thought of semantics as a branch of mathematics. However, most of his contemporary followers are as convinced as their colleagues in other fields of linguistics that their theoretical proposals must eventually be integrated with results in cognitive neuroscience. ${ }^{1}$ What, in my view, the debate is ultimately about is whether or not there is an explanatorily interesting subject matter at all for this research undertaking roughly within the contours envisaged by its practitioners: i.e., a subject matter for a theoretical account with such empirical consequences.

In Literal Meaning (2004), François Recanati clearly and helpfully articulates reasons that he has been propounding in the past two decades for adopting one of the two main contrasting positions in this debate, which he labels 'Contextualism' and 'Literalism' - the book helpfully distinguishes importantly different versions of the two views that have been advanced by participants in the debate, and in particular more or less radical versions of Contextualism, the view which Recanati himself embraces. The two views are initially characterized as follows:

According to the dominant position, which I call 'Literalism', we may legitimately ascribe truth-conditional content to sentences, independently of what the speaker who utters this sentence means. Literalism contrasts with another view, reminiscent of that held by ordinary language philosophers half a century ago. That other view, which I call 'Contextualism', holds that speech acts are the primary bearers of content. Only in the context of a speech act does a sentence express a determinate content. (2004, p. 3)

No theorist will ever be fully satisfied with the characterization that others give of views which he cares about - particularly if it is a rival theorist's characterization. Given not just the characterization above, but also its application to particular cases and the arguments that he provides for Contextualism and against Literalism, I take myself to be a literalist of sorts, although I would not fully endorse Recanati's definition - at least, not without nuances that will be more helpfully stated towards the end of this paper.

\footnotetext{
${ }^{1}$ Heim and Kratzer 1998, and Larson and Segal 1995 are two representative textbooks of the tradition I have in mind, otherwise presupposing different theoretical frameworks.
} 
In this critical note I question some aspects of Recanati's arguments and views that I take to be problematic, two of them in particular: firstly his methodological argument that the contents posited by literalists (which, on my view of the enterprise, are those that theoreticians in the formal semantics tradition I have just mentioned seek to characterize) play no relevant role in communication, and secondly some phenomenological aspects of the "Availability Principle" that he appeals to in order to buttress that main argument. In order to set my specific criticisms in a proper light, however, I see a need to first clarify the version of Literalism to which I subscribe and what I take to be the main reasons for it, even if only in a very general and quasidogmatic form; and this will occupy a good part of the paper. In the first section - and with the goal of being in a position to support my main accusation against contextualists, viz. that their views would make little sense of the deliverances of formal semantics - I provide a sketchy characterization of what I take these theories to be about. In the second section, I rely on Kent Bach's work to distinguish two notions of what is said, one in response to Grice's views, which I take to represent a pragmatic, speech-act notion, and another which is closer to characterizing the subject-matter of formal semantics; I go on to classify the different current views about the semanticspragmatics divide relative to that distinction. In the third section, I discuss a version in King and Stanley (2005) of the methodological argument that I wish to oppose, which they also support with dubious phenomenological claims; the fact that we can find similar arguments in authors otherwise defending antithetic views provides evidence for my classification in the previous section, and facilitates my task in the fourth and final section, where I finally articulate my criticisms of Recanati's book. Before we start, let me emphasize once more how illuminating the book has been for the clarification of my own understanding of these problems, both the views and concerns of the opposition, and the weaknesses in stances such as my own.

\section{The Nature of Linguistic Theories in General and Semantic Theories in Particular}

Let us start with what all participants in the debate share. They all accept the existence of some clear-cut cases of Gricean conversational implicatures, which should be accounted for roughly along the lines indicated by Grice, and that pragmatics has to do paradigmatically with such matters. Let us take as an example a remark by Bill Clinton. In a famous post-Super Bowl interview on 60 Minutes, the 
host Steve Kroft asked, "you're categorically denying that you ever had an affair with Gennifer Flowers?" Clinton answered: "I've said that before, and so has she." Although the answer was technically correct, six years later he would admit that it was "misleading" - he did have an affair. ${ }^{2}$ Here we can take Clinton to have uttered (1); we can also assume that by uttering (1) he meant something like (2), but this "meaning" of something like (2) by his uttering (1) is not anything that semantics has to account for.

(1) I've said before that I never had an affair with Gennifer Flowers, and so has she

(2) I categorically deny that I ever had an affair with Gennifer Flowers

Cases of conversational implicature like this are paradigm examples of Grice's "speaker meaning"; they are paradigm cases of a rational, intentional activity of a peculiar sort whose peculiarity lies in something along the lines that Grice was trying to capture, or of what Strawson later labeled 'communicative intentions'. Of course, the proper way of explicating that notion has generated a raging debate of its own, but we can assume that we have sufficient understanding for present purposes.

Here the agreement ends. Let me now state what I take to be the main non-negotiable concern guiding the literalists' thought. It is that natural languages must essentially consist of a relatively fixed syntactic and semantic compositional structure, independent of the vagaries of the specific intentions and arbitrary decisions of particular speakers in particular speech situations, which constrains what those specific intentions and decisions can achieve. The point, and the justification for it, was clearly articulated in the early twentieth century by Frege in the opening paragraph of "Gedankengefüge" and by Wittgenstein in the Tractatus; thus the latter says in 4.02 that we can see that a proposition is a picture of reality "from the fact that we understand the sense of a propositional sign without its having been explained to us" (I assume here that the demonstrative "this' occurring in 4.02 refers to material in 4.01, the paragraph immediately preceding it in the order indicated by their numbers). Competent speakers cannot understand the meanings of unfamiliar lexical items

\footnotetext{
2 The contrast between "technically correct" and "misleading" is made in those very words by Garry Wills in "The Tragedy of Bill Clinton", New York Review of Books, vol. 51, no. 13, 2004, p. 62, whence I have taken the details of the anecdote.
} 
in their languages unless they are "explained" to them; but they can understand the meaning of phrases which they encounter for the first time built from familiar lexical items by means of familiar modes of syntactic composition, without being in need of such explanation.

Wittgenstein linked this fact essentially with the capacity speakers have for appreciating the logical validity of inferences, and took it to have, a priori, just one possible explanation provided by his picture theory: to wit, that clausal phrases in natural language (and matching items in the mental "language" of the thoughts they express) correspond to the reality they might represent in a strong sense, by sharing a common "logical" structure. What matters to us right now is not the correctness of any such purported explanation, but to have clearly in focus the phenomenon itself in need of such an explanation; for this, I fear, is what contextualists wantonly disregard. Several decades after Frege's and Wittgenstein's remarks, Chomsky built, on the basis of the need to account for that phenomenon, a successful empirically oriented research undertaking, of which, as I said before, most contemporary practitioners of formal semantics take their discipline to be a fundamental part. To have a convenient label for the phenomenon in need of explanation, I will borrow a term from Jerry Fodor, calling it systematicity.

On the most recent presentation of his views (Hauser, Chomsky and Fitch 2002), plausibly less dogmatically reductive than previous ones, the Chomskian suggested explanation involves positing a psychologically real system at the core of the subject-matter that grammarians in general and formal semanticists in particular purport to characterize - even if only in an approximate way, abstracting from the details of the neurological configurations, or even the procedural algorithms implementing the system in particular, instances of language perception and production. This system is thought of as a specifically dedicated and biologically constituted "module" or "faculty" which, at its narrow core, features a recursive computational mechanism accounting for systematicity which, as I have said, is the phenomenon that literalists mostly focus on. In addition to the recursive module, the system is also understood to feature other components, including a "conceptual-intentional system".

The evidence that linguistic theories in general and their semantic components in particular try to account for includes, primarily, intuitions of competent speakers. This claim is not at odds with the role so far assigned to systematicity, for systematicity itself is in fact manifested by these intuitions: while competent speakers cannot have 
intuitions constituting competent understanding of phrases including lexical items that they have not encountered before, they do have them concerning clausal phrases they come across for the first time. I take linguistic intuitions to be conscious occurrent mental states, playing with respect to our linguistic knowledge a role analogous to the one ascribed in epistemology to experience - corresponding to conscious occurrent states in the case of perceptual knowledge. Perceptual experiences typically cause corresponding perceptual judgments (constitutively so, in my view), and justify them; but they should be distinguished from those judgments. The judgments could occur without the experience; and collateral information may prevent the judgment occurring, even in the presence of the experience.

To illustrate: look intensely at a bright red surface with the right eye closed for thirty seconds; then look alternatively to the surface with the right and left eyes. Collateral information about the facts of neural fatigue would lead a knowledgeable subject to suspend the perceptual judgment concerning the color of the surface that the experience caused by the overexposed left eye calls for: the experience (as of a brownish red surface) can exist without the judgment. Moreover, knowledge of the situation (information just obtained from the fresh right eye, together with knowledge of facts about color persistence) would lead knowledgeable subjects to judge that the color of the surface is still bright red, even when looking with the fatigued left eye. (A perceptual judgment can exist without the corresponding experience - as in the case of the red surface, where the experience itself is not there, even if the subject is imagining or remembering the quality just obtained through the fresh right eye; a perceptual experience is a mental occurrence with a distinctive "force", in addition to a content - a "force" distinguishing it from imaginings and rememberings, even those with overlapping contents.) Still, experience provides defeasible, prima facie justification; the foreseeable judgment induced by the fatigued eye in the inexperienced subject is at least prima facie justified. ${ }^{3}$

I think these three points - that there can be experience without judgment, judgment without experience, and that the presence of the experience provides defeasible prima facie justification for the judgment - similarly apply in the case of linguistic intuitions. I will illustrate this with an example of semantically relevant intuitions, closer to our present concerns. A competent speaker would find true,

\footnotetext{
${ }^{3}$ Pryor 2000 provides an excellent discussion, although I myself would prefer to conceptualize the issues along other lines than his dogmatist view.
} 
even obviously so, utterances of 'that table is a table'. Competent speakers would have a similar, intuitively based tendency to judge true, even obviously so, utterances of 'there are fewer even integers than integers'. Knowledgeable speakers would withhold judgment, but the intuition-based tendency would still be there. On the other hand, knowledgeable speakers would judge true "there are not fewer even integers than integers', without supporting intuitions. And the naive, intuition-based judgment that "there are fewer even integers than integers' is obviously true is, I think, prima facie justified.

Philosophers and linguists have advanced in recent years different ontological views about what is constitutive of natural languages - the subject-matter for linguistic theories; different such views would provide different glosses on the role of linguistic intuitions. From the "Platonist" perspective of Soames (1984) and, more recently, Devitt (2003), natural languages are abstract mindindependent structures, ontologically akin to what, on intuitive assumptions, logical and geometrical theories seek to characterize. From this point of view, intuitions merely have a heuristic role; we are, after all, in Neurath's ship, and thus we have to rely on any given sources of belief we might find ourselves saddled with; but, given that intuitions do not constitute in any way the linguist's object of study, there is no reason why in the end they could not prove to be entirely on the wrong track (Soames 1984, pp. 160, 174n). On the Chomskian view, linguistic theories characterize, at an abstract level, a "subpersonal" cognitive faculty causally responsible for linguistic performance. Intuitions are part of that performance, caused by the faculty of language together with other causally relevant factors. Given the influence of those additional factors, they can be misleading; but they are still a proper object of study for linguists. Any other manifestation of the true causal nature of the relevant cognitive mechanism is of course relevant for its study, famously including "poverty of stimulus" facts about acquisition and facts about the generation of creoles out of pidgins, displacing what intuitions suggest, or providing data were intuitions are silent.

The remaining two views to be sketched here differ from the preceding two in ascribing to natural languages a constitutively normative character. The pristine Gricean view is as individualistic as the Chomskian one, but, unlike the latter, takes personal (albeit "tacit") cognitive states as constitutive of natural languages, as opposed to subpersonal states. Natural languages are "procedures in the repertoire" of speakers, intentionally designed to efficiently carry out their communicative intentions; linguistic intuitions manifest the 
tacit design and intentions, and the constitutive norms are norms of rationality specific for the properly linguistic purposes and beliefs. I find this view misguided, for the reasons summarized by Schiffer (1993). However, I find Schiffer's quasi-Chomskian alternative equally unwarranted. Thus, in a well-known passage Chomsky says:

The commonsense notion [...] has a normative-teleological element that is eliminated from scientific approaches. [...] Consider the way we describe a child or a foreigner learning English. We have no way of referring directly to what that person knows: It is not English, nor is it some other language that resembles English. We do not, for example, say that the person has a perfect knowledge of some language $L$, similar to English but still different from it. What we say is that the child or foreigner has a "partial knowledge of English," or is "on his or her way" toward acquiring knowledge of English, and if they reach the goal, they will then know English. Whether or not a coherent account can be given of this aspect of the commonsense terminology, it does not seem to be one that has any role in an eventual science of language. (1986, p. 16)

Like Davies (2000), I think that incompatibilist views (both those which take only as constitutive normative features of languages, and those which take only subpersonal features) are based on misleading philosophical simplifications. A scientific approach can and should preserve the "normative-teleological" element of the ordinary notion of a natural language.

On my own view, ${ }^{4}$ natural languages are constitutively irreducibly social; they are social devices with social functions, and consist in part of social norms, such as norms constitutive of conventions. Unlike Schiffer and Chomsky, I do not find any incompatibility between this and the Chomskian view, putting aside its reductive claims. Conceptually, perception involves perceptual experiences with a normative role (they justify prima facie perceptual beliefs); however, conceptually also (as causal theories of perception emphasize), perceptual experiences play a causal role. Similarly, to be a party to a convention (for instance, one governing the use of a given lexical item, partially constituting a given natural language) involves not just normative aspects, but causal aspects too; one should have acquired (and then retained) the capacity to use the item from a certain source, say. More in general, it is not just natural kinds on the Putnam-Kripke model

\footnotetext{
${ }^{4}$ García-Carpintero 2001 presents some aspects of this.
} 
that are constituted by features only knowable through empirical research; so-called "response-dependent" kinds, such as perhaps colors, tastes, and natural languages, are also thus constituted, in addition to being constituted by features that they are known to have a priori. ${ }^{5}$

\section{Conceptions of What Is Said}

I have outlined different views about what is constitutive of natural languages, and the role these different views assign to linguistic intuitions, firstly because the semantics/pragmatics divide is in my view ultimately about which meaning-properties are constitutive of natural languages and which are not; ${ }^{6}$ and secondly because the debates we are about to examine turn to a significant degree on the role intuitions play regarding that divide. With this background, I move now to the critical discussion of some of Recanati's points.

I have already expressed my concern that Contextualism wantonly disregards the requirements of accounting for systematicity. Here is a quotation in which Recanati espouses the view:

[I]n this book I want to argue for Contextualism. According to Contextualism, the contrast between what the speaker means and what she literally says is illusory, and the notion of 'what the sentence says' incoherent. What is said (the truth-conditional content of the utterance) is nothing but an aspect of speaker's meaning. That is not to deny that there is a legitimate contrast to be drawn between what the speaker says and what he or she merely implies. Both, however, belong to the realm of 'speaker's meaning' and are pragmatic through and through. (2004, p. 4)

I will argue later that the book gives us little reason to embrace these contextualist radical claims, and also that Recanati himself manifests an unstable attitude regarding them.

Let us focus now on what is said. Grice introduced this notion into the present dispute, in his struggle to isolate a "region of signification which has special claims to centrality". ${ }^{7}$ Retrospectively, he identifies two features "which I shall call respectively "formality" and "dictiveness", with seemingly equally strong claims to provide for us a rationally reconstructed interpretation of the initially hazy feature of "centrality"; the first is saliently present in cases "in which the

${ }^{5}$ This is argued for in García-Carpintero (forthcoming-a).

${ }^{6}$ García-Carpintero 2004 elaborates on this question.

${ }^{7}$ As he reports in his 1987 "Retrospective Epilogue", Grice 1989, p. 359. 
items or situations signified are picked out as such by their falling under the conventional meaning of the signifying expression rather than by some more informal or indirect relationship to the signifying expression"; the second, in "those instances of signification in which what is signified either is, or forms part of, or is specially and appropriately connected with what the signifying expression (or its user) says as distinct from implies, suggests, hints, or in some other less than fully direct manner conveys" (Grice 1989, pp. 359-360). His earlier proposals about what is said purported to combine the two features. On the one hand, he had explicitly appealed to formality: "In the sense in which I am using the word say, I intend what someone has said to be closely related to the conventional meaning of the words (the sentence) he has uttered" (1989, p. 25). On the other, he had indicated $(1989$, pp. 30, 34) that in cases of irony or metaphor the speaker merely "makes as if to say" the semantic content of the sentence he utters. Following Bach (1994), I assume this is a tacit appeal to dictiveness; Grice is assuming that it would be intuitively wrong to think of the speaker in those cases as directly committing himself to that content.

Now, the Gricean notion is intended to elaborate on an ordinary one; we make ascriptions of what utterances and their utterers say, and have intuitions on the conditions under which they are correct. The Gricean conception thus appears to support a certain intuitive constraint on the deliverances of acceptable semantic theories, which Cappelen and Lepore (1997, p. 278) call 'MA' and state thus: an adequate semantic theory $\mathrm{T}$ for a language $\mathrm{L}$ should assign $\mathrm{p}$ as the semantic content of a sentence $\mathrm{S}$ in $\mathrm{L}$ iff in uttering $\mathrm{S}$ a speaker says p. They then go on to criticize this particular link between what is said and the deliverances of correct semantic theories, by pointing out the intuitive correctness of reports of what is said in which this departs well beyond what any theoretician would expect from a semantic theory. ${ }^{8}$

Recanati rightly claims (2004, pp. 15-16) that intuitions about reports of what is said do not provide the best approach to a theoretically significant notion of what is said. Richard (1998) has also argued, against Cappelen and Lepore's conclusions, that what he calls the "received view", $\mathrm{RV}$, is not touched by their examples. $\mathrm{RV}$ is the claim that an adequate semantic theory $\mathrm{T}$ for a language $\mathrm{L}$ should assign $\mathrm{p}$ as the semantic content of a sentence $\mathrm{S}$ in $\mathrm{L}$ in a literal utterance $\mathrm{u}$ iff $\mathrm{u}$ says $\mathrm{p}$. An intuitive motivation that Richard provides

${ }^{8}$ The theme is further developed in chapter 13 of Cappelen and Lepore 2005. 
for RV is that "uttering sentences conveys information; semantic theory tells us how information is conventionally assigned to sentence utterances $[\ldots]$. Since bits of information are what we convey by assertively uttering sentences, semantic theory tells us what we say when we speak literally" (1989, p. 605). However, as we are about to see, Richard's conclusion does not follow from his premises; and RV needs clarification.

The beginning of a proper understanding of what is said, and its link with the deliverances of semantic theories, is in my view illuminated by Kent Bach's insistence that Grice's two criteria, formality and dictiveness, in fact point to different notions. Bach thinks that they can be usefully explicated by appealing to

Austin's distinction between locutionary and illocutionary acts. Austin, it may be recalled, defined the locutionary act $[\ldots]$ as using certain "vocables with a certain sense and reference" [...]. That sounds a lot like Grice's notion of saying, except that for Grice saying something entails meaning it: the verb 'say', as Grice uses it, does not mark a level distinct from that marked by such illocutionary verbs as 'state' and 'tell', but rather functions as a generic illocutionary verb that describes any constative act whose content is made explicit. (1994, p. 143)

Bach proposes to amend Grice, avoiding some intuitively odd aspects of his views:

There was one respect in which Grice's favored sense of 'say' was a bit stipulative. For him saying something entails meaning it. This is why he used the locution 'making as if to say' to describe irony, metaphor, etc., since in these cases one does not mean what one appears to be saying. Here he seems to have conflated saying with stating. It is most natural to describe these as cases of saying one thing and meaning something else instead [...]. Besides non-literality, there are two other reasons for denying that saying something entails meaning it. A speaker can mean one thing but unintentionally say something else, owing to a slip of the tongue, a misuse of a word, or otherwise misspeaking. Also, one can say something without meaning anything at all, as in cases of translating, reciting [...]. So we can replace Grice's idiosyncratic distinction between saying and merely making as if to say with the distinction (in indicative cases) between explicitly stating and saying (in Austin's locutionary sense). (Bach 2001, p. 17)

Bach's notion of saying, explicated in terms of Austin's notion of locutionary act, is of course closely related to Grice's formality feature, 
while his illocutionary notion (properly restricted to indicative cases) of explicitly stating is closely related to dictiveness; not to prejudice present issues, I will call them what is $\operatorname{said}_{L}$ and what is said $_{I}$, and cognates. ${ }^{9}$

The tension between the two Gricean criteria for what is said is not merely manifested by Grice's contortions concerning saying vs. merely making as if to say; Grice had also noticed the problem posed by his "conventional implicatures", which, according to the formality criterion, make it what is said, while, according to the dictiveness criterion they do not. This is one of the reasons why he characterizes what is said as merely "closely related" to the conventional meaning of words. Properly put, the point is that, while conventional implicatures do not belong (at least, in the case of utterances of atomic sentences) in what is said $_{I}$, they do belong in what is $\operatorname{said}_{L}$. In a recent paper, Barker (2003) defends what I take to be this view, and he interestingly uses it to object to theories of meaning that seek to reduce linguistic meaning to truth-conditions. He wants to argue, with Grice, that while (i) is what is said by (3), and thus what determines its truth-condition, not just (i), but also (ii) is part of (3)'s semantic content, "the content it possesses by virtue of linguistic rules and context, and upon which logical particles may potentially operate" (2003, p. 2).

(3) Even John could prove the Completeness Theorem

(i) John could prove the Completeness Theorem

(ii) It is comparatively improbable that John could prove the Completeness Theorem

Barker provides convincing evidence for the latter claim: the semantic embeddability of what is indicated, or conventionally implicated, as part of the content to which some operators are sensitive (2003, pp. 8-13). In previous work I myself have argued that, while referential expressions such as indexicals and proper names contribute their referents to the content asserted in utterances of simple subject-predicate declarative sentences where they occur - as direct-reference theorists contend-, some reference-fixing descriptive material contributes to merely indicated conventional implicatures, and thus to semantic content, against the most radical tenets

\footnotetext{
${ }^{9}$ Salmon 1991 and Ziff 1972 have related distinctions. As will become clear, the proposal I outline, although along the same lines, differs in its details from them and from what Recanati calls "the Syncretic View" (2004, pp. 51-54).
} 
of those theorists. ${ }^{10}$ Part of my argument was the traditional Fregean one that those contents can be semantically embedded under indirect discourse operators. ${ }^{11}$

The case of conventional implicatures thus shows that we need a notion of what is $\operatorname{said}_{L}$ distinct from the truth-conditional or properly propositional notion of what is $\operatorname{said}_{I}$, and, on the assumption that semantic theories should give us the constitutive meaning properties of natural languages, it is clear that what is $\operatorname{said}_{L}$ is a semantic

${ }^{10}$ García-Carpintero 2000. Following Stalnaker's considerations (1974, 2002), I analyze there the relevant Gricean conventional implicatures - merely indicated but nonetheless semantic contents - as pragmatic presuppositions, as opposed to semantic presuppositions (requirements for the truth of the sentence encoding it and its negation). The relevant contents are semantic (part of what is $\operatorname{said}_{L}$ ), in that they are part of the conventional meaning of some expressions, in that they account for the felt validity of some inferences, in that they embed under some operators, and so on. But they should be analyzed in terms of the pragmatic notion of what speakers believe to be part of the common ground they accept, as argued by Stalnaker, because such an explication is appropriately more flexible. It allows that in some cases (perhaps (5) is one of them) the fact that the indicated content fails to obtain is compatible with the truth or falsity of the utterance; while in some other cases (say, cases of failure of identifying conditions for referents) this is not so. The view also allows for a theoretically more satisfactory account of presupposition projection, and for there being a form of presupposition cancellation.

${ }^{11}$ Failure to notice our distinction, however, mars Barker's discussion. In present terms, the Gricean view that Barker wants to defend is one about what is $\operatorname{said}_{I}$. In order to defend it, Barker feels compelled to discredit Bach's 1999 arguments that conventional implicatures are part of what is said. Once our distinction is made, however, the apparent inconsistency between Barker's and Bach's claims is easily seen to be at most terminological. For Bach does not argue that conventional implicatures are part of what is $\operatorname{said}_{I}$. On the contrary, he adopts here the same line we have seen him suggesting in other work: "intuitions about what is said tend to conflate what is said with what is asserted, which may include less than the full propositional content of the utterance. What is asserted is the content of an illocutionary act, not the locutionary act of saying. What is said comprises the full content of the locutionary act (the semantic content of the utterance), but that may include more than what intuitively is taken to be asserted" (1999, p. 344n). Bach provides a semantic embeddability argument, analogous to Barker's, for his view that conventional implicatures are part of what is said, based on the specific case of the indirect discourse 'says' operator. He appeals to his 'IQ test' (1999, pp. 338-343), which shows that in some contexts ascriptions of what is said with, say, (3) embedded are not intuitively equivalent to corresponding ascriptions with (3i) embedded instead. Thus, there does not appear to be substantive contradiction between Bach and Barker. What Bach calls 'what is asserted' is what is said , and thus what for Barker counts as what is said, coinciding with Grice's favored sense; Bach agrees that this does not include conventional implicatures. What Bach calls "what is said', on the other hand, is what is said $_{L}$, and thus what Barker counts as semantic content; and both agree that it includes conventional implicatures, for similar reasons. 
notion. ${ }^{12}$ Indexicals can be used to make the point, as I just indicated, but they can also be used to make the opposite claim, that what is said $I$ goes typically beyond what a semantic theory should be concerned to provide. But, of course, we could also use to that effect some of the many examples highlighted by Recanati and other friends of Contextualism, such as (4) and (5):

(4) It is raining

(5) The ham sandwich left without paying

Recanati distinguishes "primary" from "secondary" pragmatic processes. The latter are those involved in the generation of uncontroversial conversational implicatures, such as (2); it is in these terms that he captures the point that, as he puts it in the preceding quotation, "there is a legitimate contrast to be drawn between what the speaker says and what he or she merely implies". I will come back to Recanati's primary/secondary distinction, about which I have serious qualms; but I will firstly focus on primary pragmatic processes, on account of which, according to Recanati, what the speaker says belongs as much as implicatures do "to the realm of 'speaker's meaning" "and is "pragmatic through and through".

Among primary processes, Recanati distinguishes 'saturation' and 'modulation'. The first kind, saturation, is the process of providing values to parameters in linguistically controlled and mandated way (2004, pp. 7-10); mandated in that it is allegedly necessary in order to get a truth-evaluable proposition. Thus, the sentence (4) does not by itself express a proposition that can be evaluated as true or false. We at least need to add a time, which is normally provided as the time of utterance. It is usually held that a location needs to be provided as well; if a location value is required, then adding one is also an example of saturation. If a location value is not required, and no one is provided, then an utterance of (4) at a time $t$ expresses that it is raining somewhere at $t$, which is true or false. If a location value is optional, as Recanati holds, then providing a location value is an example of what Recanati calls 'free enrichment' (2004, p. 10). Free enrichment is a kind of modulation; modulation goes beyond saturation: it is not required for reaching a truth-evaluable proposition, but pragmatically added. A kind of modulation is semantic transfer, exemplified by (5) as said by one waiter to another. The phrase "the

\footnotetext{
${ }^{12}$ García-Carpintero 2004 invokes to the same effect the fact that moods conventionally signify aspects of illocutionary force.
} 
ham sandwich' is used to refer to the ham sandwich orderer, rather than to the sandwich; the semantic value has been transferred from the latter to the former.

In sum, thus, Recanati rejects views such as Cappelen and Lepore's (1997) that there is no theoretically significant undertaking seeking to relate with clausal items what is said by means of them; this theoretically privileged notion of what is said is the one that would be captured by Grice's two criteria of formality and dictiveness. On what in my view is the most illuminating way of classifying opposing views on the semantics/pragmatics divide, this represents the common assumption to one of the two confronted sides. Apart from this, there are important differences among writers I would put on this side in the debate. Writers whom Recanati calls 'minimalists' mostly agree with him on the classification of signified items as resulting from linguistically controlled or linguistically uncontrolled processes, but differ in taking as their theoretically privileged notion of what is said only the one determined by saturation-like processes. On the other hand, those whom Recanati calls 'indexicalists' — writers following the lead of Stanley (2000) - agree with minimalists about the latter, but disagree with them, and hence with Recanati, that most if not all of the alleged examples of items resulting from modulation-like processes are in fact linguistically controlled. ${ }^{13}$

In Bach's terms, these writers share the assumption that semantics focuses on what is $\operatorname{said}_{I}$. Perhaps they are motivated by considerations such as those by Richard (1998) quoted before in his defense against Cappelen and Lepore's (1997) skepticism of the "received view", that an adequate semantic theory $\mathrm{T}$ for a language $\mathrm{L}$ should assign $\mathrm{p}$ as the semantic content of a sentence $\mathrm{S}$ in $\mathrm{L}$ in a literal utterance $\mathrm{u}$ iff $\mathrm{u}$ says $\mathrm{p}$. Richard argued that "uttering sentences conveys information; semantic theory tells us how information is conventionally assigned to sentence utterances [...]. Since bits of information are what we convey by assertively uttering sentences,

\footnotetext{
${ }^{13}$ It should be clear that I do not have any reservations about positing "hidden variables" for the syntax-semantics interface, and in part as a result I have serious doubts concerning Recanati's criticisms of indexicalism in chapter 7; but I will not go into them, for I am sure that advocates of the view will take them up themselves (cf., e.g., Stanley 2005). My own reasons against indexicalism are, firstly and foremost, those of a fundamental character concerning the proper strategy to trace the semantics-pragmatics distinction and, ultimately, to properly account for systematicity, presently to be indicated in the main text. Additionally, I have serious doubts that positing hidden variables in the syntax is always the best way of accounting for the phenomena — doubts such as those outlined by Hawthorne 2004, pp. 98-100.
} 
semantic theory tells us what we say when we speak literally" (1998, p. 605). Now, in my view we should reject this argument on the basis of our previous considerations for semantics to focus rather on what is $\operatorname{said}_{L}$. Firstly, by assertively uttering sentences we do more than just conveying bits of information; we may also, say, conventionally convey some assumptions we take to share with our audience, and there is no good reason why semantic theories should abstain from telling us how we systematically do this. Secondly, semantic theory is in no position to give us all the information that we convey when we speak literally; it can only give us the systematic constraints on that.

Famously, for the case of indexicals Kaplan (1989) distinguished two levels of meaning, character and content. Given that there are sour debates among writers otherwise in agreement about the basics of Kaplan's framework, ${ }^{14}$ let me follow Schiffer's (2003) strategy and use instead 'character*' and 'content", assuming that these correspond to Kaplan's distinction when matters are sufficiently straightforward, such as in the case of ' $\mathrm{I}$ ' or 'yesterday'. 15 Borrowing Kaplan's distinction thus modified, we could label the two primarily opposed views about the semantics-pragmatics divide that I am distinguishing 'content*-semantics', or 'c-semantics' for short, and 'character*-semantics', 'ch-semantics' henceforth. Minimalists such as Cappelen and Lepore (2005) and indexicalists such as King and Stanley (2005) share with Recanati the view that semantics is c-semantics, in spite of their important differences; in contrast, the ch-semanticist takes it that it is rather what is $\operatorname{said}_{L}$ that semantic theories purport to characterize in a systematic way. In these terms, ch-semantics is the subject-matter famously advocated by Lewis (1980, pp. 23-24) for a semantic theory, which on his view should be "one suited to play a certain role in a systematic restatement of our common knowledge about language [...] the detailed and parochial part - the part that would be different [...] if we were Japanese". Lewis goes on to disparage more ambitious goals, such as "that a good grammar should

\footnotetext{
${ }^{14}$ There are disputes, say, about whether or not the character-content distinction applies in significant ways to proper names and natural kind terms, about whether or not (and, if so, how) it applies to expressions in linguistic categories far away from those of indexicals such as ' $\mathrm{I}$ ' and 'now', like mood-indicators, and so on.

${ }^{15}$ It should be clear, from what I said before about conventional implicatures and presuppositions being part of what is $\operatorname{said}_{L}$, i.e., of what semantics delivers, and from my suggestion that a "multi-propositional" view of the semantics of those phenomena along the lines of Bach's is on the right track, that I take characters to be too coarse for an adequate characterization of the semantic features of utterances.
} 
be suited to fit into a psycholinguistic theory that goes beyond our common knowledge and explains the inner mechanisms that make our practice possible". It should be clear from the preceding remarks that I strongly disagree with him about this.

\section{King and Stanley (2005) against Character-Semantics}

As I will explain in the next section, this view of what semantics is about constitutes a form of Literalism, in Recanati's sense, and it even sustains a form of Minimalism, albeit different from those views that take semantics to be in the business of delivering c-contents, restricted to those deriving from processes of "saturation" — such as Cappelen and Lepore (2005). Now, King and Stanley (2005) offer an argument for c-semantics that (unsurprisingly, given what I take to be their deep agreement beyond their important superficial differences) is very close to what I assume is Recanati's main argument against the form of Minimalism that a defender of ch-semantics such as myself would espouse. ${ }^{16}$ I will approach my main goal in this paper, to express my main concerns about Recanati's book, the issues regarding which I would like to press him to elaborate in his reply, in a roundabout way, by first taking issue with the related arguments by King and Stanley. My reasons for this are dialectical: they make the points more bluntly, and are thus easier and clearer targets for my criticisms. In the next section I will explore the extent to which they apply to Recanati's less straightforward claims.

King and Stanley (2005, pp. 121-126) distinguish three different conceptions of the deliverances of ch-semantics, and they rightly reject two of them; although it should be clear to any reader of, say, Kaplan 1989, Lewis 1980 or Stalnaker 1978 that none of these were confused about the matter, their point is well taken. To make the proper connection with the themes I have been emphasizing so far, thereby justifying the length of the path I have been following, I will put what I take to be the main common consideration against those two first interpretations as follows. A semantic theory takes as its starting point evidence of linguistic intuitions, in particular those manifesting systematicity. To account for that, it compositionally ascribes semantic features to complex expressions (sentences, in particular), on the basis of features of lexical units and syntactic modes of combining them. Now, if we pay attention to relevant linguistic

${ }^{16}$ Of course, Recanati does not explicitly discuss the view; but I assume that he would extend to it the main arguments he gives against Minimalism and other forms of Literalism. 
intuitions, we will see that in most common cases it is the content of lexical items that is directly involved in the compositional building up of complex semantic features; the two conceptions that King and Stanley initially consider wrongly ignore this.

To illustrate, there is an obvious intuitive semantic difference between 'John loves Mary' and 'Mary loves John'. On the present view, the character*/content* distinction applies to 'John', 'Mary' and even 'loves'. Now, if we consider particular utterances, it may well be that the contents of 'John' and 'Mary' are the same; and also that "loves" signifies the very same "neutral relation" in both cases (see Fine 2000). On what - compatibly with these assumptions (which are not Fine's) - I take to be the most plausible explanation of the difference, syntactic features of the NPs result in different (proto-)thematic roles, agent and theme, being associated with them (see Dowty 1991). Now, these roles are in fact relational properties that the NP-contents have vis-à-vis the VP-content. The semantic value of the complex expression (the sentence) appears thus to result from semantic features of the mode of combination (the relevant syntactic features, being the subject, being the direct object) applied to the contents* of the lexical units, not to their characters*. ${ }^{17}$ Notice that I am not appealing here to intuitions about how meanings are composed in "real time" (which I myself lack), but only about the most plausible explanation of intuitions about meanings of complex expressions.

Now, as King and Stanley (2005, pp. 126-127) acknowledge, this point is compatible with the Lewisian view that semantic theories are fundamentally intended to account for systematicity by delivering characters*. As an illustration, they consider the sentence 'I am here', which they regiment as 'Located(I, Here)', and, writing ' $\mathrm{C}(e)$ ' for the character* of expression $e$, and suppressing detail, suggest this as a character* for it:

(6) $\mathrm{C}\left({ }^{\prime} \operatorname{Located}(i, p)\right.$ ') for ' $i$ ' an individual term and ' $p$ ' a position term $=$ $f$ such that for any context $c, f(c)=\left\langle C\left({ }^{6} i\right)(c), \mathrm{C}\left({ }^{\circ} p^{\prime}\right)(c)\right\rangle$

They still have two objections to this, most plausible version of the view about the semantics/pragmatics divide I am embracing here.

\footnotetext{
${ }^{17}$ Usual presentations of the concept of compositionality are noncommittal on whether the modes of combination themselves might contribute semantic features; even more so concerning whether they could be context-dependent with respect to those semantic features. See Pagin 2005 for a precise, detailed and interesting discussion.
} 
The first is an undisguised, and in my view empirically totally implausible, appeal to nonexistent (speaking for my own case), or at least non-authoritative, linguistic intuitions:

Our first concern is that such an account intuitively assigns the wrong semantic significance to syntactic combination [...]; the semantic significance of the syntactic concatenation here is that of a function that maps a pair of a function $f$ from contexts to objects and a function $g$ from contexts to properties to a function $h$ that maps a context $c$ to the pair $\langle f(c), g(c)\rangle$. This seems grossly implausible as the meaning of the syntactic relation of predication. Furthermore, it simply does not seem that in understanding such a sentence in a context, speakers employ this compositional semantics to determine a character for a sentence, and then apply it to the context yielding the relevant structured proposition. Intuitively, it seems rather that speakers evaluate in a context the characters of syntactically simple expressions in a sentence, and compositionally combine the resulting referential contents in grasping the proposition expressed by the sentence. Thus, the account seems to get the phenomenology of linguistic understanding wrong. (King and Stanley 2005, p. 127)

There are two phenomenological points in this quote. To me, the first reads as if a linguist criticized a rival's claim about syntactic structure (say, a claim about a specific postulation of "movement") on the basis of alleged intuitions about how the grammaticality of a particular sentence is determined on the basis of properties of its constituents. There are linguistic intuitions relevant for the ascription of syntactic structure (say, intuitions about intonation and prosodic patterns, or about ways of inserting phrases from a foreign language in one's native language); but ordinary speakers lack the intuitions the authors appeal to, or, if some do have them (I cannot speak for King and Stanley phenomenology), they carry no authority. How do you feel about how the meaning of being the subject (the proto-thematic role agent, if the previously outlined view is correct) is applied to the meaning of the relevant NP? This is a "grossly implausible" question to ask. The second phenomenological point in the text is even weirder. One does not need to be as skeptical as Chomsky is regarding performance theories to dismiss any suggestion that how the compositional semantics, or the compositional syntax, is employed in particular cases of language use is a matter to be decided by direct appeal to intuitions. We simply lack significant intuitions about those matters. King and Stanley rightly emphasize 
the important role that intuitions have for linguistic theorizing; in my view, appeals to intuitions like theirs are the best way to encourage skeptics.

King and Stanley's second argument is methodological, and prima facie more compelling:

both a semantics that assigns characters to simple expressions and recursively assigns characters to complex expressions and a semantics that assigns characters to only simple expressions allow for an assignment of the same contents in contexts to simple and complex expressions. So unless the functional characters of complex expressions have some additional job to do, they are unnecessary. But there seems to be no such additional job. (2005, p. 128)

Nevertheless, it is only prima facie that this argument is more compelling. The first, and most important thing to notice in reply is this: on the assumption that the semantics assigns characters* to the lexical units and modes of composition, it already assigns thereby characters* to the phrases and other compounds these modes of composition determine. In other words, there was no need for King and Stanley's long and difficult empirical study to come up with characters* for complex expressions such as the one illustrated by (6); all that was required was some logical ingenuity —or, better put, some familiarity with the technicalities of the relevant framework (such as, of course, Kaplan (1989), Lewis (1980) or Stalnaker (1978) were capable of, and took for granted in their readers). The point is that theories that correctly ascribe their semantic significance to lexical units and modes of combination already logically entail ascriptions of semantic values to the complex expressions they help to build. They must do, because, if properly devised, in ascribing semantic significance to modes of composition they are already built in such a way as to have those consequences. ${ }^{18}$

\footnotetext{
${ }^{18}$ This point merits more extended discussion (thanks to Jason Stanley for pointing this out); Davidsonians need to put heavy constraints on the logic of their preferred semantic theory in order to satisfy their contention that correct semantic theories deliver interpretative T-theorems. It should be clear that I reject any such view, but the matter requires further study. In any case, King and Stanley do not suggest that their main argument against ch-semantics thus depends on a controversial view about the nature of semantic theories, at odds with the practice of most linguistically oriented semanticists. This is perhaps a convenient place to insist once again (cf. note 15) that to properly design the semantics so that it ascribes their correct significance to modes of combination is not so easy as the toy illustration of-
} 
So, what kind of "additional" job could they have in mind? Is it that the theoretician, in addition to stating in the axioms of his theory the characters* for lexical units and modes of composition, devotes some time to deriving theorems (which would of course correspond, in an empirically more accurate way, to what (6) attempts to illustrate)? I admit that the latent sarcasm in this rhetorical question might seem unfair, and I have some more plausible interpretative suggestion to make below; if I allow myself the rhetoric, it is only because I want to insist that their argument should be dismissed at this point, before going into the more controversial claim I will be making presently. King (2003, p. 235) sums up the argument thus:

I am in fact somewhat skeptical as to whether a semantics assigns to sentences (and other syntactically complex expressions) characters at all $[\ldots]$. It may be that only the syntactically simple parts of sentences are assigned characters by the semantics. One might hold this because one doesn't think that the characters of sentence parts are combined compositionally by the semantics to yield the character of a whole sentence.

What would it mean for the semantics "to combine compositionally the parts to yield" the characters for complex expressions? If the semantics is properly designed, it already yields complex characters, as a matter of its logic.

As I said, this is the main point I wanted to make in reply. But there is a second one, a bit more controversial, which I have already suggested and is worth making too; to wit, that there are in fact "additional" jobs for characters for sentences to do. Lewis (1980) claims that there is no significant difference between the style of semantics he advocates, in which the theory ascribes "constant, but complex" meanings to sentences, and the one advocated by Kaplan (1989) and Stalnaker (1978), in which it rather ascribes them "variable, but simpler" contents: to all theoretical purposes, they are mere notational variants. This is one of the places where my differences with Lewis, noticed before, over whether psychological facts about linguistic competence matter for linguistic theorizing, do make a

fered by (6) might suggest to those not familiar with minimally empirically plausible contemporary semantic theorizing. This was one of my motivations for mentioning, above, facts about conventional implicatures. The notion of 'character*' abstracts away, just for present purposes of philosophical discussion, from all that detail and nuance, of course crucial for the proper conduct of the empirical enterprise. 
difference: I would not be so cavalier about the differences between those theories. However, for present purposes Lewis' point stands. Stalnaker and Kaplan both grant a crucial place in their theories to contents (as I myself would do, even if I do not think it is the task of semantics proper to deliver them, and even if semantics proper in my view goes beyond them), just as King and Stanley would. Nonetheless, their full accounts all include characters*, and characters* for whole sentences among them.

Take Stalnaker's (1978) view; he would ascribe to sentences what he calls "propositional concepts", represented by well-known twodimensional matrixes. They are needed, according to him, because the matrixes include propositions additional to those constituting the, as it were, official contents of sentences, which he calls "diagonal" contents (on account of their location in those representations). For these contents are, on Stalnaker's view, "what is said" in some cases (ordinary assertions of identity statements, say), and the semantic value of some embedded sentences (in some ascriptions of propositional attitudes). Like ordinary contents, these are typically pragmatically enriched too, by means of extra-linguistic information from context, but they have a purely linguistic core: as I mentioned before, the conventional implicatures that are constitutive of the characters* of some sentences can become straightforward content-constituents when they are embedded under some operators. Kaplan (1989), for his part, would claim that characters* for sentences are needed to provide a "logic for demonstratives"; they are, roughly, the contents whose truth is preserved in some inferences to whose validity the intuitions of ordinary speakers are sensitive. I have argued (García-Carpintero, forthcoming-b) that such characters are similarly needed to account for our intuitions about the truthconditions of vague, or more generally indeterminate, statements; they are, roughly, "what is said", as this is reconstructed in supervaluationist settings.

These points require much more elaboration than I can provide here, but they at least suggest that King and Stanley's challenge can be answered in their own terms; characters* for sentences are needed in the sense that a complete semantic theory should not just entail them (as I insisted before, a semantic theory already includes them, if it includes the characters* that King and Stanley are prepared to grant), but also refer to or quantify over them, and in the related sense that some relevant linguistic intuitions of speakers are 
directly sensitive to them (strictly speaking, to contents determined by them). ${ }^{19}$

\section{Recanati's Methodological and Phenomenological Arguments}

As I mentioned before starting this discussion of King and Stanley's views, as far as I understand it Recanati's main argument for Contextualism requires him to share their criticism of ch-semantics; I find in the book versions (independently elaborated, I assume) of their methodological argument, buttressed by unrelated, but similarly dubious phenomenological claims. If I am right, they are equally objectionable. I shall now attempt to demonstrate this, and finally make clear my principal misgivings with the book along with the questions I would like to put to him.

There is in my view a reliance on phenomenological considerations - as questionable as the one I have just denounced in King and Stanley's work - in Recanati's recourse to his Availability Principle, which distinguishes him from other friends of Contextualism, in particular Relevance Theorists; in fact, the point I want to make here is very close to one apparently made by Robyn Carston, to which Recanati replies in chapter 3 -unsuccessfully, I will argue. We have seen that Recanati distinguishes primary from secondary pragmatic processes: the latter account for implicatures, such as (2); the former are responsible for determining what he counts as what is said. This is the way he makes the distinction:

Secondary pragmatic processes are 'post-propositional'. They cannot take place unless some proposition $p$ is considered as having been expressed, for they proceed by inferentially deriving some further proposition $q$ (the implicature) from the fact that $p$ has been expressed. In contrast, primary pragmatic processes are 'pre-propositional': they do not presuppose the prior identification of some proposition serving as input to the process. Another difference is the fact that secondary pragmatic processes are conscious in the sense that normal interpreters are aware both of what is said and of what is implied and are capable of working out the inferential connection between them. Primary pragmatic processes are not conscious in that sense. (2004, p. 23)

\footnotetext{
${ }^{19}$ See in addition Cappelen and Lepore's arguments against what they call the "psychological argument" (2005, ch. 12), and their related argument against Contextualism in chapter 8; of course, I would not base these points on the minimal contents provided by their c-semantics (contents obtained merely by saturation of indexicals, the category meanly conceived on the basis of an excessively meager theoretical vision), but on those described in the main text.
} 
The phenomenological fallacy that I imputed to King and Stanley consisted in that, in order to defend their view against, in particular, a literalist ch-semantics proposal such as the one I have been sketching, they appeal to non-existent —or at least non-authoritative consciously available - data. In making this distinction between primary and secondary processes, Recanati is incurring, I think, in this very same fallacy. Notice firstly how important the distinction is for his purposes in the context of this debate. I have been insisting that the way we trace the semantics/pragmatics divide is not a merely terminological matter, and he would concur with me about this. Acceptable proposals should delimit, as it were, a natural kind for semantic theories to deal with: an interesting explanatory domain. On his view, only his notion of what is said - crucially characterized relative to this distinction between primary and secondary processes - properly answers to that concern; only such a notion provides the proper delimitation. In particular, my own alternative - what is $\operatorname{said}_{L}$, the subject-matter for ch-semantics - does not. I assume this, because otherwise I do not see how he could sustain the main claims in his espousal of Contextualism in an already quoted text, repeated here:

According to Contextualism, the contrast between what the speaker means and what she literally says is illusory, and the notion of "what the sentence says' incoherent. What is said (the truth-conditional content of the utterance) is nothing but an aspect of speaker's meaning. That is not to deny that there is a legitimate contrast to be drawn between what the speaker says and what he or she merely implies. Both, however, belong to the realm of 'speaker's meaning' and are pragmatic through and through. (Recanati 2004, p. 4)

It is the appeal to the availability considerations that allows Recanati to maintain the existence of a "legitimate contrast" between what is said and what is implied, and to sustain in addition the strong claim that "what is said" is either "pragmatic through and through" or, otherwise, an "incoherent" notion. Now, prima facie it seems that, to serve this purpose, the distinction he makes should apply to the actual processes involved in implicature production and interpretation, vs. those involved in understanding what is said, in his privileged sense. In the end, as we will see, under pressure from Carston's well taken criticisms, this is not what he commits himself to; but that is a concession which, as far as I can see, makes it difficult to sustain the strong claims he makes in the quoted text. In any case, that the distinction is made concerning what goes on 
in actual processes is what the wording above suggests. The book is peppered with many other related passages suggesting the same; thus, he says that for primary processes to take place, "there is no need to antecedently compute the proposition literally expressed" (2004, p. 27; for present purposes, we can take the "proposition literally expressed' to be the character*, or a content determined by it), while "conversational implicatures are inferentially derived from premises concerning the speaker's intentions in saying what he says" (2004, pp. 38-39); "there is something special about" their interpretation, "it is a two-step procedure. The interpreter first determines the utterance's primary meaning, then infers some additional meaning" (2004, p. 74, the emphasis is Recanati's in all three quotes).

It should be clear that I agree with Recanati on the importance of the notion of what is said $_{I}$; characters* for declarative sentences are functions from contexts to those contents. However, I think that what is $\operatorname{said}_{L}$ is rather the theoretically fundamental notion for present purposes, the one delimiting a natural kind which provides the subject matter for semantics. Because of that, I am not prepared to grant that considerations such as Recanati's isolate a privileged role for what is $\operatorname{said}_{I}$ vis-à-vis what is $\operatorname{said}_{L}$. Now, those considerations depend on whether or not some conscious inferences occur. Like King and Stanley's, they rely on phenomenological data. However, the required pieces of phenomenological evidence are here similarly missing. The Clinton example was given with the intention of illustrating this. With the goal of getting away, if the need arises, by invoking the intuitive distinction between lying and misleading, ${ }^{20}$ public figures such as Clinton are very good at exploiting the simple fact that the actual inferential processes through which we derive, say, (3) from their utterances are all but conscious; we are as little aware of them as we might be of the machinery of primary pragmatic processes.

Take your favorite conception of the psychological reality of grammars. To me the one that comes closest is Peacocke. Any proponent of a view about the semantics-pragmatics divide such as the one I am advancing will say that characters* are psychologically real in that sense. In particular, the subpersonal mechanisms responsible for the production and interpretation of intelligible speech acts should "draw upon" the information that the semantic theory packages into

\footnotetext{
${ }^{20}$ In a very interesting as yet unpublished work that she kindly allowed me to see, Jennifer Church explores the relevance of this intuitive distinction for evaluating proposals about the semantics/pragmatics divide.
} 
the relevant characters*; compatibly with this, he will want to suggest that what Hauser, Chomsky, and Fitch (2002) would classify as part of the "conceptual-intentional system" also plays an important role. This is compatible with Recanati's views on primary pragmatic processes: the actual processes involved in giving rise, in real time, to what he counts as what is said can be characterized as inferences, but they are merely inferences at the subpersonal level, in which "what is literally expressed" (the character*, on the present view) plays no role as a premise in a conscious inference. The present point is that the same applies to secondary processes in actual cases.

The literalist must insist on this, in part because he gives an important role in his general theoretical framework to generalized conversational implicatures; and the point that, in producing and interpreting implicatures in real time, what is literally expressed (what is said, on his own privileged sense) plays merely a subpersonal contribution is even clearer in that case. ${ }^{21}$ Now, this is an empirical claim, which can be faulted on empirical grounds; perhaps neuroscientific evidence might show that the relevant mechanisms do not "draw upon" the information that the semantics provides in the same way in both processes, primary and secondary. But Recanati is in no position to give this kind of argument; his theoretical palette includes just the resources available to the philosopher, his consciously available intuitions and the conceptual distinctions he can make on their basis.

The present point is, in sum, that the deployment of availabilitybased considerations to isolate, as a theoretically privileged notion, saturated and freely enriched contents vis-à-vis characters* is also an instance of the phenomenological fallacy we saw before in King and Stanley. As I said before, Recanati considers an objection like this, made by Carston; in reply, he goes dispositional (2004, pp. 43, 50). There is still, he contends, a dispositional availability-based distinction between primary and secondary processes, in that the inferences involved in the latter on the basis of what is said (in his sense) are consciously available.

In previous works, together with Kent Bach and other writers, I have expressed doubts - which Recanati (2004, pp. 161-165) critically discusses, without in my view providing any reason to alleviate them - that there is an asymmetry even at this dispositional

\footnotetext{
${ }^{21}$ The proposal in Bontly 2005 to inerpret Gricean appeals to “Modified Occam's Razor" in terms of empirically explanatory issues, specifically related to language acquisition, is very congenial to the general tenor of my proposals here, and to the present point in particular.
}

Crítica, vol. 38, no. 112 (abril 2006) 
level, now for the opposite reasons. Characters* are not contents in the ordinary sense; they are not propositions that can be objects of intentional acts like assertion, belief, assumption or consideration. However, appealing to two-dimensionalist ideas I contended above, in my reply to the methodological argument by King and Stanley, that characters* do determine more minimal propositions which are sometimes objects for acts such as those, and are always available for them. I believe that, in this way, conscious intuitions that we are dispositionally capable of eliciting support rational reconstructions of the actual subpersonal inferences from characters* to saturated and freely enriched contents, analogous to those provided by Grice for Recanati's secondary processes. Competent speakers have a priori access to features of the meanings of the lexical units and modes of composition, manifested for instance in inferences (among them, those that a Kaplanian "logic of demonstratives" purports to systematize). It is to be expected that this knowledge sustains dispositions to entertain minimal propositions related to characters*, and to accept rational reconstructions of the subpersonal inferences, producing in context saturated and enriched contents out of them. ${ }^{22}$

Perhaps I can exploit at this point the analogy with the epistemology of perception that I appealed to before, in the first section. The contents conscious experience makes perceptually available to us are very rich; they are about things like buildings and computers, or even about gamma-particles in the case of certain scientists, represented as such. There are good reasons for epistemology to restrict the contents for which experiences themselves provide justification to more fundamental ones, concerning the distribution of observational features like shapes and colors in the scene around the subject. It would be silly to try to support this view on claims about the role of those contents in actual conscious inferences; this is contradicted by what our phenomenology tells us. At the most, one can say, if one has a sensibly naturalistic attitude towards epistemology, that the mechanisms supporting the actual subpersonal

${ }^{22}$ To reinforce the point, see again the arguments by Cappelen and Lepore (2005) mentioned in note 19. Recanati (2004, p. 165) criticizes me for demanding "more availability than I do". As these remarks suggest, this is in a way correct. But I hope that what I say in the main text clarifies a little bit more the view I was trying to put forward in the paper that Recanati was criticizing. The conscious intuitions that are crucially important on my view for present matters are those that Recanati himself also emphasizes, those typically resulting from unconscious processes of modulation, manifesting systematicity. The theoretically privileged notion for the semantics/pragmatics divide is in my view the one required to explain them, in a crucial part by appeal to non-linguistic knowledge. 
inferences should "draw upon" the minimal contents that one's epistemology ascribes to experiences. Compatibly with this, one can additionally support this epistemological view with the not at all silly phenomenological claim that competent ordinary perceivers are in a position to have conscious access to the minimal contents. And I think one should make this claim, if one's epistemology is not only sensibly naturalistic, but also, compatibly with this, properly sensitive to the consequences regarding the personal/subpersonal distinction of the normative dimension of the notion of justification. I think that these merely impressionistic suggestions about the personal and subpersonal roles of the minimal contents of experiences apply, mutatis mutandis, to characters* and the minimal contents they determine in the case of the epistemology of language understanding.

To repeat, I am not saying that there is no relevant distinction between what is said on Recanati's view, and what is implicated. On the contrary, I have been insisting that there is a very important one: saturated and enriched contents of declarative sentences, unlike those conversationally (or conventionally, for that matter) implicated, have the dictiveness feature that Grice correctly isolated; as I have been emphasizing, they are the "values" of those "functions" by means of which we are abstractly representing the meanings of those sentences for present purposes. However, it is precisely the fact that we have at our disposal such an explanatory notion,

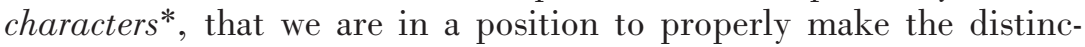
tion.

In his introductory chapter, Recanati puts an explanatory challenge on minimalists:

On the one hand, there are prototypical cases of implied meaning, in which the participants in the speech situation are aware both of what is said and of what is implied, and also of the inferential connection between them. On the other hand, there are [cases of saturation and enrichment]. Given his willingness to treat [them] as conversational implicatures external to what is literally said, the minimalist must explain why those implicatures, unlike the prototypical cases $[\ldots]$, do not have the property of conscious 'availability'. (2004, pp. 11-12)

Much later, after having seen him wrestling with Carston's objection, we realize that the word 'external' was not otiose; after having acknowledged, in effect, that claims of conscious awareness in prototypical cases such as this are too quick off the mark (Is not the 
Clinton implicature "prototypical"?), he ends up appealing, against the minimalist, to a distinction of his own between the duality of what is said vs. what is implicated, which is indeed "external", and the duality of minimal vs. enriched and saturated contents, which is rather "internal":

What is special is the perceived inferential link between the primary and secondary meanings. In internal-duality cases, there is a duality but no inferential relation between the two components. The extra element - the perceived inferential link - is what gives substance to the distinction between the two types of case. $(2004$, p. 81)

This is perhaps the clearest instance where the phenomenological fallacy is being committed. The phenomenology does not evince such an asymmetry; what is more important, by itself the phenomenology cannot support the explanatory burden placed on it. It is actually Recanati's views that do not stand up to the explanatory challenge, properly understood.

To summarize this main point against Recanati's phenomenological views: only what goes on in actual processes appears to matter for the argument; and Recanati concedes that, at that level, no significant difference is forthcoming between primary and secondary processes. How could a mere capacity to reproduce, by means of a conscious inference, the merely subpersonal one that is granted to occur in implicature production and understanding account for the distinction between what is said and what is implicated? I am assuming here that the notion of what is said, for all parties involved, is intended to delineate a sufficiently natural kind, a sufficiently well defined subject-matter for empirical theorizing, by appeal to which interesting explanations can be given. The merely dispositional asymmetries that Recanati in the end appeals to, even granting for the sake of the argument that they exist, do not allow for that. It is not merely that talk of different processes to account for the distinction between saying and implicating would be misleading, if in the end the distinction does not depend on the processes themselves, but on potentialities whose relation to them remains unexplained. It is rather that one does not distinguish instances of an explanatorily interesting category from others in terms of potentialities that the latter allegedly lack, unless one is in a position to relate the potentialities to categorical properties that the former have. The proponent of ch-semantics is in a position to do that; for he claims that it is 
the characters* of utterances that constitute an interesting subjectmatter for an explanatory undertaking, and hence he is in a position to say that they relate to what for Recanati counts as what is said in a different (say, more direct) way, than they do to what is implicated. But I cannot see how the contextualist can. ${ }^{23}$

Or perhaps he can, in fact, if the contextualist is of Recanati's persuasion; but this is only because of some other aspect of his views that renders them even more obviously unstable. We are now already in the terrain of the methodological argument; for, as with King and Stanley, this is Recanati's main argument for the strong claims constituting his Contextualism: "As I have been at pains to emphasize, the minimal proposition is not computed, and does not play a role in the actual process of interpretation" (2004, p. 161). Now, in general what he has in mind by 'Minimalism' is views such as Cappelen and Lepore's (2005), on which semantics delivers contents resulting merely from saturation of obvious, manifest indexicals. But he does not have any problem with meanings such as my characters*; and he is even prepared to grant that they determine contents, which (following Perry's version of the Stalnakerian twodimensionalist view) he calls 'reflexive propositions' (2004, p. 56n; pp. 65-67). The question here is how could this acceptance be made compatible with Contextualism? There is, in my terms, a non-illusory contrast between what the speaker literally says, and what she means; the notion of 'what the sentence says' is not incoherent at all; and, last but not least, we may legitimately ascribe truth-conditional content to sentences, (sufficiently) independently of what the speaker who utters this sentence means... (in accordance with a sensible way of interpreting) the dominant position, 'Literalism'. (In some sense,

\footnotetext{
${ }^{23} \mathrm{My}$ objection here is, as I have indicated, the very same as that put forward by Relevance theorists. However, this is just another version of Contextualism. This seems to confirm Stanley's suspicion (2005) that at the end of the day there is no important difference between Minimalism (I guess he would consider my view as a form of that) and Contextualism. (It is mildly curious that writers equally intent as Stanley and myself upon giving pride of place to contemporary linguistically informed formal semantics feel like resorting to the very same rhetorical trick of placing the opposition in what we both take to be the bad company of Contextualism; for, of course, this is what I have been doing so far, insisting that Stanley's and Recanati's views are similar in being both instances of c-semantics, and also in the type of argument they tend to appeal to.) The difference is perhaps one of emphasis, but no less important because of that. Relevance theorists acknowledge the role in language use of what linguists theorize about; but I do not feel that they properly appreciate its importance and its complexity. There is also the related point that the reply to be given to the methodological argument also applies to them.
} 
on that interpretation speech acts are still the primary bearers of content, in accordance with 'Contextualism'; hence my misgivings, expressed at the beginning, about Recanati's characterization of the Literalism/Contextualism divide.)

My worry about the methodological argument, then, is that it is inconsistent with other things that Recanati accepts; when he makes his radical-sounding contextualist claims, he appears not to be attending to some of his considered views, which are actually incompatible with them. Lexical units and modes of combination constitute natural languages, and have fixed meanings, independently of the vagaries of the particular intentions of individual speakers in particular speech situations; this is why Humpty-Dumpty was wrong, and you cannot mean whatever you intend to with them. ${ }^{24}$ And this is why sentences have meanings, even though individual speakers in actual speech situations never use them that way ( ${ }^{6} 1.257$ is odd and 1.257 is not odd', to give an obvious example). Those meanings even determine contents that might rise to the conscious attention of speakers, which they can assert, or even refer to when ascribing propositional attitudes; and there are good reasons for this, deriving from the normative aspects of language understanding. Recanati acknowledges all of this. The mystery for me is that he can still go on to subscribe to Contextualism. He does say that characters", and the "reflexive" propositions they determine, "don't quite correspond to what one standardly means by a "complete' proposition" (2004, p. 56n). Perhaps he is right; c-semantics is more standard these days. Of course, there are the good precedents that I have mentioned, including Lewis 1980. And, above all, if I am right, contemporary formal semanticists are all in the business of building theories determining characters* for sentences. In any case, how can this admission be made consistent with the claims that the contrast between speaker and literal meaning is illusory, and the latter notion incoherent?

Recanati's worry might perhaps be another. If one is focusing on examples like 'this moves' or 'he is ready', it is easy to complain that characters* and the "reflexive" contents they determine are very meager indeed, of very little interest in comparison with their saturated and enriched contents in context. Well, interesting is interest-relative. I suggested above a sketchy proposal regarding the contribution to characters of syntactic features such as being the subject and being the object. Now, if one has a look at recent lin-

\footnotetext{
${ }^{24}$ This is the obvious (but no less forceful because of that) main anti-contextualist
} point that Cappelen and Lepore 2005 and Stanley 2005 rightly emphasize. 
guistically informed discussions of these matters (cf. Baker 1997 for illustration), one will see how actually complicated and "interesting" the issues are, especially in that they obviously relate to empirical issues. (Issues regarding the comparison between different natural languages: whether or not "ergative" languages such as Basque and "accusative" languages such as English or Spanish ultimately signify proto-thematic roles in the same way is immediately relevant here; issues concerning the acquisition and evolution of language, and so on.) Toy examples like 'this moves' and toy representations of characters* such as (6) perhaps divert attention from the otherwise obvious fact that any empirically accurate account of the semantic data, systematicity in particular, is going to be very complicated and "interesting". It is of that complexity that, I fear, contextualists do not appear to take proper notice. ${ }^{25}$

\section{REFERENCES}

Bach, Kent, 2001, “You Don't Say?", Synthese, vol. 128, pp. 15-44.

- 1999, "The Myth of Conventional Implicatures", Linguistics and Philosophy, vol. 229, pp. 327-366.

-, 1994, "Conversational Impliciture", Mind and Language, vol. 9, no. 2, pp. 124-162.

Baker, Mark, 1997, "Thematic Roles and Syntactic Structure", in L. Haegeman (ed.), Elements of Grammar, Kluwer, Dordrecht, pp. 73-137.

Barker, Stephen, 2003, "Truth and Conventional Implicature", Mind, vol. 112, pp. 1-33.

Bontly, Thomas D., 2005, “Modified Occam's Razor: Parsimony, Pragmatics, and the Acquisition of Word Meaning", Mind and Language, vol. 20 , no. 3, pp. 288-312.

Cappelen, Herman and Ernie Lepore, 2005, Insensitive Semantics, Blackwell, Oxford.

, 1997, "On an Alleged Connection between Indirect Speech and the Theory of Meaning", Mind and Language, vol. 12, pp. 278-296.

Chomsky, Noam, 1986, Knowledge of Language: Its Nature, Origin and Use, Praeger, New York.

${ }^{25}$ Research for this paper is supported in the framework of the European Science Foundation EUROCORES programme "The Origin of Man, Language and Languages" by the Spanish Government's grant MCYT BFF2002-10164 and research project HUM2004-05609-C02-01, by the DURSI, Generalitat de Catalunya, SGR010018, and by a Distinció de Recerca de la Generalitat, Investigadors Reconeguts 2002-2008. My views on these matters have evolved in the course of extended discussions about them with Ambròs Domingo. I am also grateful to Peter Pagin, Esther Romero and Jason Stanley for comments on a previous version. I am also indebted to Michael Maudsley for his grammatical revision. 
Davies, Martin, 2000, "Persons and their Underpinnings", Philosophical Explorations, vol. 3, pp. 43-62.

Devitt, Michael, 2003, "Linguistics Is Not Psychology", in A. Barber, Epistemology of Language, Oxford University Press, Oxford, pp. 107139.

Dowty, David, 1991, "Thematic Proto-Roles and Argument Selection", Language, vol. 67, no. 3, pp. 547-619.

Fine, Kit, 2000, "Neutral Relations", Philosophical Review, no. 109, pp. 133.

García-Carpintero, Manuel, 2004, "Assertion and the Semantics of ForceMarkers", in C. Bianchi (ed.), The Semantics/Pragmatics Distinction, CSLI Lecture Notes, The University of Chicago Press, Chicago, pp. 133166.

__ 2001, "Gricean Rational Reconstructions and the Semantics/Pragmatics Distinction", Synthese, vol. 128, pp. 93-131.

— 2000, "A Presuppositional Account of Reference-Fixing", Journal of Philosophy, vol. 97, no. 3, pp. 109-147.

—_, forthcoming-a, "A Non-Modal Conception of Secondary Properties", Philosophical Papers.

—_ forthcoming-b, "Bivalence and What Is Said", Dialectica.

Grice, H.P., 1989, Studies in the Way of Words, Harvard University Press, Cambridge, Mass.

Hauser, M., N. Chomsky and W.T. Fitch, 2002, "The Faculty of Language: What Is It, Who Has It, and How Did It Evolve?", Science, vol. 298, pp. 1569-1579.

Hawthorne, John, 2004, Knowledge and Lotteries, Oxford University Press, Oxford.

Heim, I. and A. Kratzer, 1998, Semantics in Generative Grammar, Blackwell, Oxford.

Kaplan, David, 1989, "Demonstratives", in J. Almog, J. Perry and H. Wettstein (eds.), Themes from Kaplan, Oxford University Press, Oxford, pp. 481-563.

King, Jeffrey, 2003, "Tense, Modality, and Semantic Values", Philosophical Perspectives, vol. 17, Language and Philosophical Linguistics, Ridgeview, Atascadero, pp. 195-245.

King, Jeffrey and Jason Stanley, 2005, "Semantics, Pragmatics, and the Role of Semantic Content", in Z. Szabo (ed.), Semantics vs. Pragmatics, Oxford University Press, Oxford.

Larson, Richard and Gabriel Segal, 1996, Knowledge of Meaning: Semantic Value and Logical Form, MIT Press, Cambridge, Mass.

Lewis, David, 1980, "Index, Context, and Content", in S. Kanger and S. Öhman (eds.), Philosophy and Grammar, Reidel, Dordrecht. (Reprinted in David Lewis, Papers in Philosophical Logic, Cambridge University Press, Cambridge, 1998, pp. 21-44.) 
Montague, Richard, 1973, "The Proper Treatment of Quantification in Ordinary English", in Hintikka, J., J. Moravcsik and P. Suppes (eds.), Approaches to Natural Language, Reidel, Dordrecht, pp. 221-242.

Pagin, Peter, 2005, "Compositionality and Context", in G. Preyer and G. Peter, Contextualism in Philosophy: Knowledge, Meaning and Truth, Oxford University Press, Oxford.

Peacocke, Christopher, 1986, "Explanation in Computational Psychology: Language, Perception and Level 1.5", Mind and Language, vol. 1, pp. 101-123.

Pryor, James, 2000, "The Skeptic and the Dogmatist", Noûs, vol. 34, pp. $517-549$.

Recanati, François, 2004, Literal Meaning, Cambridge University Press, Cambridge.

Richard, Mark, 1998, "Semantic Theory and Indirect Speech", Mind and Language, vol. 13, pp. 605-616.

Salmon, Nathan, 1991, "The Pragmatic Fallacy", Philosophical Studies, vol. 63, pp. 83-91.

Schiffer, Stephen, 2003, "Knowledge of Meaning", in A. Barber, Epistemology of Language, Oxford University Press, Oxford, pp. 303-324.

—_, 1993, "Actual-Language Relations", in J. Tomberlin (ed.), Philosophical Perspectives, vol. 7, Language and Logic, Ridgeview, Atascadero, pp. 231-258.

Soames, Scott, 1984, "Linguistics and Psychology", Linguistics and Philosophy, vol. 7, pp. 155-179.

Stalnaker, Robert, 1978, "Assertion", in P. Cole (ed.), Syntax and Semantics, vol. 9, Academic Press, New York, pp. 315-332. (Reprinted in R. Stalnaker, 1999, Context and Content, Oxford University Press, Oxford, pp. 78-95.)

Stanley, Jason, 2005, "Review of François Recanati's Literal Meaning", Notre Dame Philosophical Reviews, on-line at: http://ndpr.nd.edu/reviews.cfm.

- 2000, "Context and Logical Form", Linguistics and Philosophy, vol. 23, pp. 391-434.

Ziff, Paul, 1972, "What Is Said", in D. Davidson and G. Harman (eds.), Semantics of Natural Language, D. Reidel, Dordrecht, pp. 709-721.

Received: January 17, 2006; accepted: February 1, 2006. 